\title{
CONCEPT OF USING FRUIT POMACE ON SUSTAINABLE FARMS
}

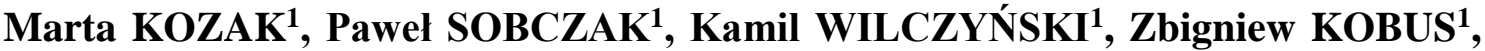 Kazimierz ZAWIŚLAK ${ }^{1}$, Wioletta ŻUKIEWICZ-SOBCZAK ${ }^{2}$}

${ }^{1}$ Department of Food Engineering and Machines, University of Life Sciences in Lublin, POLAND

${ }^{2}$ Pope John Paul II State School of Higher Education in Biała Podlaska, Department of Public Health, Regional Center Research of Environment, Agriculture and Innovative Technology EKO-AGRO-TECH, POLAND

E-mail of the corresponding author: kozak-marta@wp.pl

Keywords:sustainable farms, agglomeration, antioxidant activity, polyphenols, pomace

\begin{abstract}
The paper presents the possibility of using fruit pomace as the management of poor products on sustainable farms. Processing of raw materials in the fruit and vegetable industry involves generation of manufacturing waste, of which pomace that may be processed in different ways, constitutes the highest share. Pomace is most commonly used as fuel in biogas plants, or as feed additives. Despite its high microbial instability, pomace is a great source of numerous bioactive substances. Therefore, it may be used alternatively in the production of granulated fruit and herbal teas.The aim of this paper was to assess the possibility of using fruit pomace in the production of granulated teas with addition of Melissa officinalis. Material used in the study was the agglomeration of dried and fragmented black chokeberry and apple pomace blended with Melissa officinalis. Prepared granules were used to make infusions for which the total polyphenol content, antioxidant activity and sediment amount were determined.
\end{abstract}

\section{INTRODUCTION}

Pomace constitutes the largest group of manufacturing waste generated during fruit and vegetable processing. Significant amounts of pomace produced in a relatively short time span pose a considerable problem for entrepreneurs, as it is highly perishable. What is more, due to high water content reaching as much as $73 \%$, microbial development processes can start very quickly. Immediate pre-treatment of generated pomace allows solving this problem, however only to some extent. Despite its high microbial instability, pomace is a great source of numerous bioactive substances, such as flavonoids, tannins, anthocyanins or fibre. It is a relatively inexpensive and easily accessed raw material, used most commonly as feed additives. Its chemical composition enables to significantly reduce costs related to animal feeding. Pomace may also be processed into biogas or biofuels. It may also be used in the manufacture of colourants and acquisition of fibre (Kruczek et al. 2016, Tańska et al. 2016).

Waste materials coming from fruit and vegetable processing contain a considerable amount of strong antioxidants - phenols in particular, which play a highly important role in determining the nutritional value and sensory characteristics. They are able to protect the body against the activity of free radicals, thus preventing heart diseases, cancer, cataract, and slowing the ageing processes (Dobson et al. 2015, Kozak et al. 2016, Tańska et al. 2016). Due to their health promoting properties, an alternative pomace management solution may be production of fruit teas. Such teas are growing in popularity, and they have started to outsell black teas available on the market. They are characterized by specific flavour and aroma, and they have high nutritional value. They are often enriched with herbal additives to increase their content of bioactive substances (Almajano et al. 2008, Szlachta\&Małecka 2008, Zych\&Krzepiło 2010).

The aim of this paper was to assess the possibility of using chokeberry and apple pomace in the production of granulated teas. Material used in the study was the agglomeration of 
dried and fragmented pomace with Melissa officinalis. Prepared granules were used to prepare infusions for which the content of total polyphenols and antioxidant activity were determined. Amount of sediment was also measured.

\section{MATERIALS AND METHODS}

The material used in the study was fruit and herbal infusions prepared from agglomerated pomace, with addition of lemon balm (Melissa officinalis L.). Chokeberries (Galicjanka variety) and apples (Daret variety) were obtained from private plantations in the Lubelskie province. The fruit were of high quality, they were properly ripe and juicy. Chokeberryfruit was frozen and stored at $-18^{\circ} \mathrm{C}$ for 24 hours. Chokeberry pomace was obtained by pressing the thawed fruit, using a laboratory fruit press manufactured by RECHT company. Fresh apples were pre-crushed and pressed using the same device. Fruit pomace was dried in an air flow drying machine (POL-EKO), in order to obtain the moisture level of $8 \%$. Next, dried fruit were ground using a lab grinder (WŻ-1 manufactured by ZBPP Bydgoszcz). Raw materials prepared in this manner were blended into chokeberry and apple mixes with 5, 10 and 15\% additions of lemon balm with particle size ranging from $0.5-1 \mathrm{~mm}$. Ready-made fruit and herbal blends were subject to non-pressure agglomeration using a disk granulator, with $40 \%$ aqueous solution of starch as the moisturizing liquid. The control samples were granules obtained bynon-pressure agglomeration of the fruit pomace. After drying and hardening the granules, they were weighed as $2 \mathrm{~g}$ portions and locked up in tea filter papers using a HENDI vacuum sealer.

Infusions were made by pouring $100 \mathrm{~cm} 3$ of demineralised water of $90^{\circ}$ Coverbags containing herbal granules, and brewing them for five minutes, covered. Produced infusions were drained through medium-pore qualitative filter paper, and weighed after drying. Difference between pure filter paper weight and its weight after draining was the basis for determining the amount of sediment present in fruit and herbal infusions.

In order to determine the total polyphenol content in fruit and herbal infusions, spectrophotometry using Folin-Ciocalteu reagent and gallic acid as a standard (Borkataky 2015, ISO 14502-1 2005) was performed. Absorbance was measured at $765 \mathrm{~nm}$ against distilled water, after 30 minutes of sample preparation. Total content of polyphenolic compounds in the infusions was expressed as gallic acid equivalents - $\mathrm{mg}$ (GAE) $100 \mathrm{~cm}^{-}$ 3 .

Antioxidant activity of fruit and herbal infusions was determined using a stable free 1,1-diphenyl-1-picrylhydrazyl radical(DPPH), using a method developed by Zych and Krzepiło (2010). Alcoholic solution of DPPH of $0.5 \mathrm{mM}$ was prepared and diluted to obtain absorbance $\left(\mathrm{A}_{0}\right)$ approximating 0.9 at $\lambda=517 \mathrm{~nm}$. Spectrophotometer was calibrated with methanol. An examined sample contained $3 \mathrm{~cm}^{3}$ of DPPH solution and $0.4 \mathrm{~cm}^{3}$ of a given infusion. Absorbance of the prepared samples (A) was measured 30 minutes after onset of the reaction. For each measurement, three independent repetitions were conducted and the average absorbance value $\left(\mathrm{A}_{\text {avg }}\right)$ was measured for a given infusion. 
The ability to quench a radical was expressed as a percent value of inhibition of the examined infusion, using the following formula:

$$
\% \text { of inhibition }=100\left(\mathrm{~A}_{0}-\mathrm{A}_{\mathrm{avg}}\right) / \mathrm{A}_{0}
$$

where:

$A_{\text {avg }}-$ average absorbance of the examined infusion containing an antioxidant,

$\mathrm{A}_{0}-$ absorbance of the solution of DPPH free radical.

Ten measurements were performed for every infusion. Obtained results were subject to statistical analysis using STATISTICA 10.0 software. Statistical significance (P) and F test value (ANOVA) were determined.

\section{RESULTS}

The examined fruit and herbal teas presented different sediment content (Fig. 1). Addition of lemon balm significantly reduced the amount of sediment found in the examined infusions. Infusions made from granulated apple pomace had nearly double sediment content when compared with chokeberry teas, which was probably the result of pulp particles penetrating into the infusions during brewing.

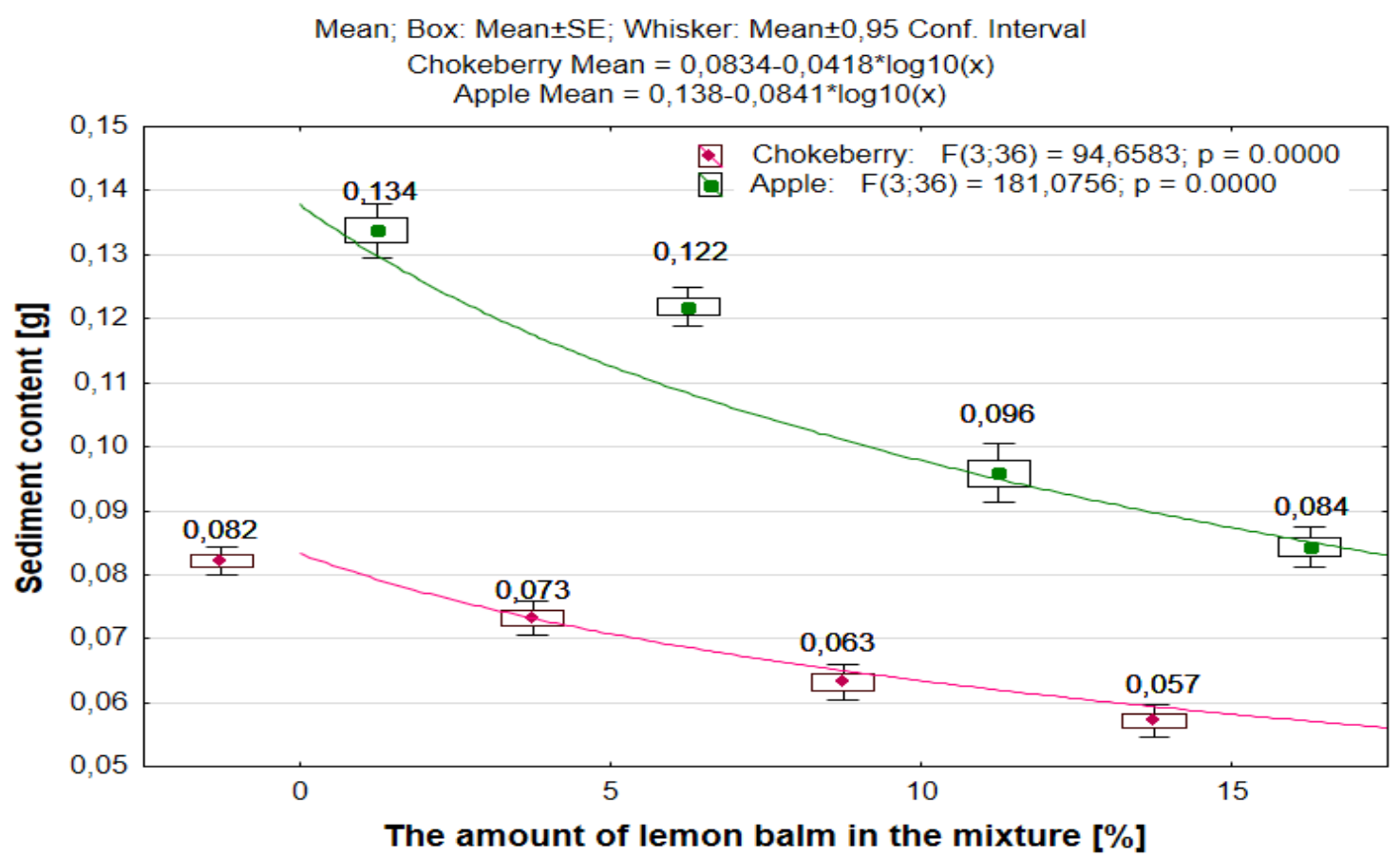

Fig. 1. Effect of lemon balm addition on fruit tea sediment content.

Fig. 2 presents the effect of lemon balm addition on total polyphenol content in fruit teas. Addition of lemon balm considerably increased polyphenol content in the examined infusions, in case of the highest share by as much as $30 \%$ in chokeberry teas and by more than $40 \%$ in apple teas. Chokeberry-based teas used as the control presented three times higher polyphenol content $\left(33.81 \mathrm{mg} \cdot 100 \mathrm{~cm}^{-3}\right)$ when compared to infusions prepared from apple pomace $\left(10.41 \mathrm{mg} \cdot 100 \mathrm{~cm}^{-3}\right)$. While examining antioxidant activity of teas and fruit dried for commercial use, Szlachta and Małecka (2008) found a similar 
relationship. Infusion made from dried chokeberries contained about $18.4 \mathrm{mg} \cdot 100 \mathrm{~cm}^{-3}$ of phenolic compounds, whereas tea made from dried apples only $4.40 \mathrm{mg} \cdot 100 \mathrm{~cm}^{-3}$. A significantly higher polyphenol content in teas prepared from granulated fruit pomace may effect from shorter pomace drying time when compared to drying of fresh fruit since, as confirmed by data available in the literature, phenolic compounds are more sensitive to higher temperatures. What is more, polyphenol content is also determined by a given variety, method and place of production, as well as raw material storage conditions (Almajano et al. 2008, Andrzejewska et al. 2015).

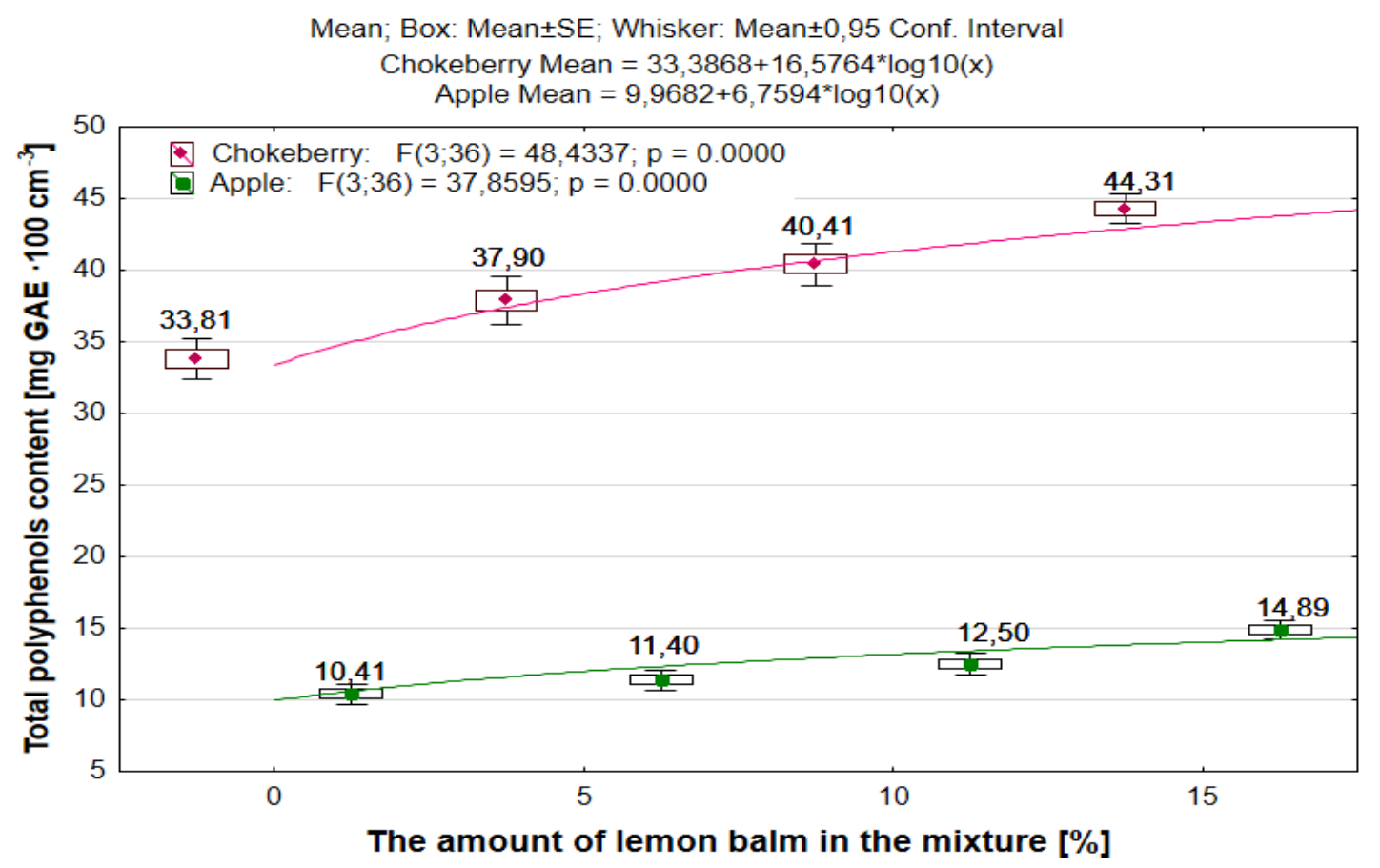

Fig. 2. Total polyphenol content in fruit teas depending on added amount of lemon balm.

As shown in numerous findings, the ability to quench free radicals is strictly related to the content of phenolic compounds (Bonarska-Kujawa et al. 2012, Borkataky 2015, Kozak et al. 2017), which was confirmed by results of the study presented in Fig. 3; it demonstrates the effect of lemon balm addition on antioxidant properties of fruit infusions. Chokeberry teas displayed a significantly higher polyphenol content, as well as higher ability to quench DPPH radical, when compared to apple-based infusions. 


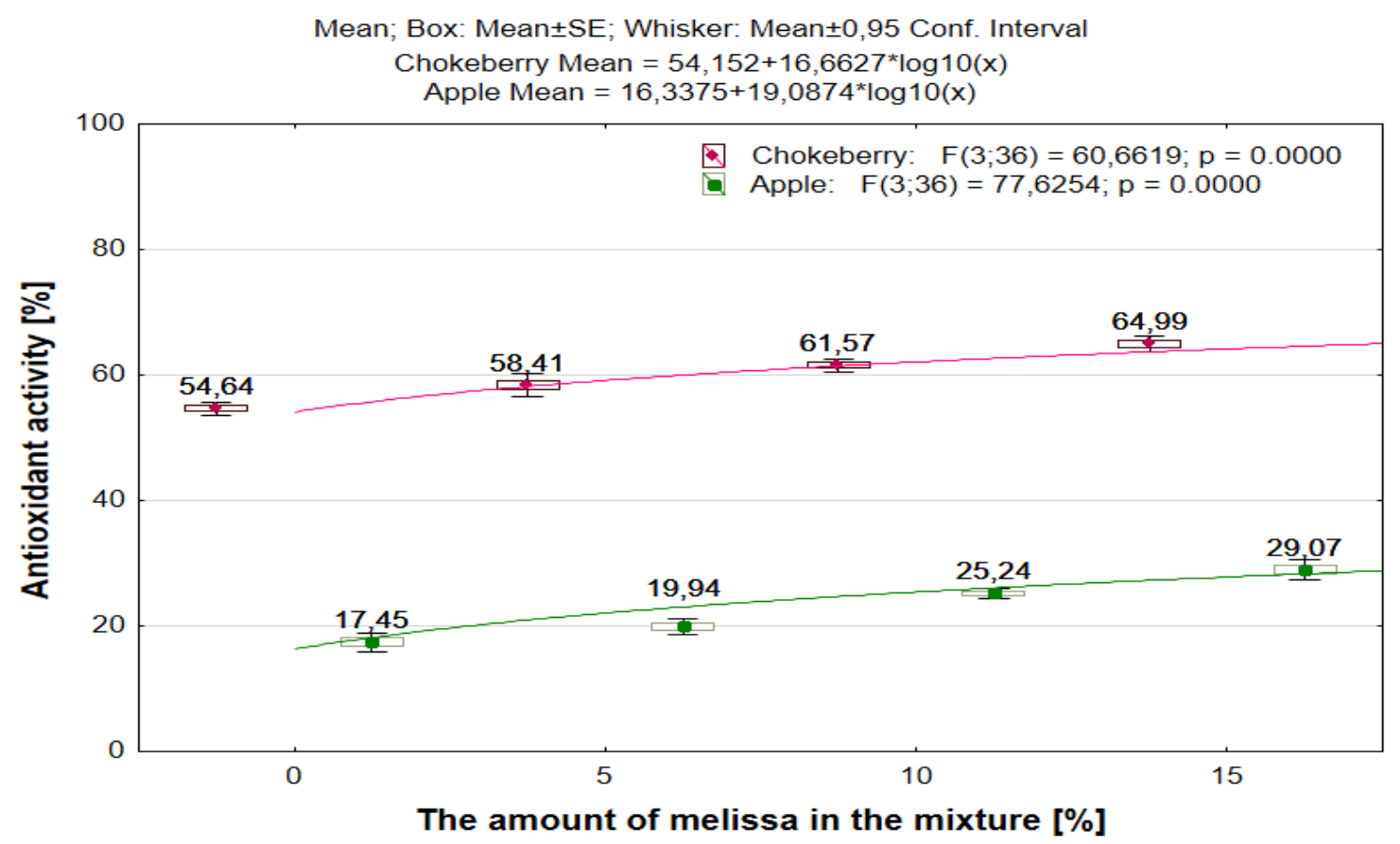

Fig. 3. Antioxidant activity of fruit teas depending on percent content of lemon balm in the mixture.

\section{CONCLUSIONS}

The study has shown that non-pressure agglomeration is an alternative method for managing fruit pomace for food uses, and that it allows obtaining new products in the form of granulated fruit teas.

Teas made from granulated apple pomace had the highest sediment content, with the average of $0.13 \mathrm{~g}$, which could result from penetration of pulp particles during the brewing process. Addition of lemon balm considerably reduced the amount of sediment found in all prepared infusions.

Infusions from granulated chokeberry pomace had three times higher content of bioactive substances when compared to apple-based teas.

Addition of lemon balm during granulation of fruit pomace increased polyphenol content and antioxidant activity in case of all fruit teas, which allowed obtaining products with high health-promoting properties that can be used as dietary supplements.

\section{REFERENCES}

Almajano, P., Carbó, R., López, J.J. \& Gordon, M.H. (2008). Antioxidant and antimicrobial activities of tea infusions. Food Chemistry, 108 (1), 55-63.

Andrzejewska, J., Sadowska, K., Klóska, Ł. \&Rogowski L. (2015).The Effect of Plant Age and Harvest Time on the Content of Chosen Components and AntioxidativePotenntial of Black Chokeberry Fruit. ACTA ScientarumPolonorum, 14 (4), 105-114.

Bonarska-Kujawa, D., Sarapuk, J., Bielski, K., Oszmiański J. \&Kleszczyńska, H. (2012).Antioxidant Activity of Extracts from Apple, Chokeberry and Stawberry. Polish Journalof Food and Nutrition Sciences, 62 (4), 229-234.

Borkataky, M. (2015). Antioxidant activity, total phenolic content and total flavonoid content of Perillaocymoides Linn. Scholars Research Library: Der Pharmacia Lettre, 7 (5), 69-72 
Dobson, G., Shrestha, M., Hilz, H.,Karjalainen, R., McDougall, G. \&Sewart D. (2012). Lipophilic components in black currant seed and pomace extracts. European Journal of Lipid Science and Technology, 114 (5), 575-582.

Gopal, K., Devi, M. \&Bhalla, T.C. (2008).Bioethanol production from apple pomace left after juice extraction. International Journal of Microbiology, 5 (2).

ISO 14502-1:2005 (2005). Determination of substances characteristic of green and black tea. Part 1: Content of total polyphenols in tea. Colorimetric method using Folin-Ciocalteu reagent.

Kozak, M., Sobczak, P., Krajewska, M., Ślaska-Grzywna, B., Wójtowicz, A., Żukiewicz-Sobczak, W. (2017).Evaluation of Health Promoting Properties and Quality of Herbal Teas Obtained from FineGrained Fraction of Herbs. Journal of Central European Agriculture, 18 (2), 388-403.

Kozak, M., Sobczak, P., Żukiewicz-Sobczak, W. (2016).Health properties of selected herbal plant. Health Problems of Civilization, 2, 64-70.

Kruczek, M., Drygaś, B., Habryka, C. (2016).Pomace in fruit industry and their contemporary potential application. World Scientific News, 48, 259-265.

Szlachta, M. \&Małecka, M. (2008). Antioxidant Properties of Fruit Teas.Food. Science. Technology. Quality, 1 (56), 92-102.

Tańska, M., Roszkowska, B., Czaplicki, S., Borowska, E.J., Bojarska, J. \&Dąbrowska, A. (2016).Effect of Fruit Pomace Addition on Shortbread Cookies to Improve Their Physical and Nutritional Values. Plant Foods for Human Nutrition, 71 (3), 2307-313.

Zych, I., Krzepiło, A. (2010). Pomiar całkowitej zdolności antyoksydacyjnej wybranych antyoksydantów i naparów metodą redukcji rodnika DPPH. Chemia. Dydaktyka. Ekologia. Metrologia, 15 (1), 51-54. 